\title{
Perception of the pregnancy management quality by pregnant women suffering from vaginismus
}

\author{
M. Hdiji, Y. Zgueb, J. Hamdoun, U. Ouali, F. Nacef \\ Razi Hospital, "A" Psychiatric Department, La Manouba, Tunisia \\ WORLD \\ PSYCHIATRIC \\ ASSOCIATION \\ $\Gamma_{19^{\text {TH }} \text { WPA WORLD }}$ \\ CONGRESS OF PSYCHIATRY \\ LISBON, 21-24 AUGUST, 2019
}

\section{BACKGROUND AND OBJECTIVES}

Vaginismus is a feminine sexual dysfunction that makes impossible any intercourse with penetration and whose exact origin is unknown, but which is compatible with pregnancy. This association is delicate, vaginismus is a pathology that is often unrecognized and poorly diagnosed by caregivers, especially in case of pregnancy, often considered as a sign of healing.

The aim of our study was to evaluate the perception of the pregnancy management quality by pregnant women suffering from vaginismus, including the follow-up and the attitude of medical and paramedical staff.

\section{MATERIALS AND METHODS}

This is a descriptive, prospective and longitudinal study that has been spread over eight months, from November 2017 to June 2018, including 40 pregnant women suffering from vaginismus who consulted the emergency department of the Maternity and Neonatology Center of Tunis. These women were followed and answered a pre-established questionnaire. The psychiatric history as well as epidemiological and clinical data were collected.

\section{RESULTS AND DISCUSSION}

- In the delivery room, the majority of women reported some of the caregiver's remarks that they found to be bothersome or disrespectful. These remarks indicate a lack of training of the health staff in the management of vaginismus in pregnant women, and for which the pregnant woman must be able to be examined by a vaginal touch because she would have necessarily had sexual intercourse for to be pregnant [1].

- The evaluation of the perception of the quality of pregnancy management by the patients, including the follow-up and the attitude of the nursing staff, is presented in the figure 1.
- The evaluation of the perception of the quality of care according to the mode of delivery is presented in table 1.

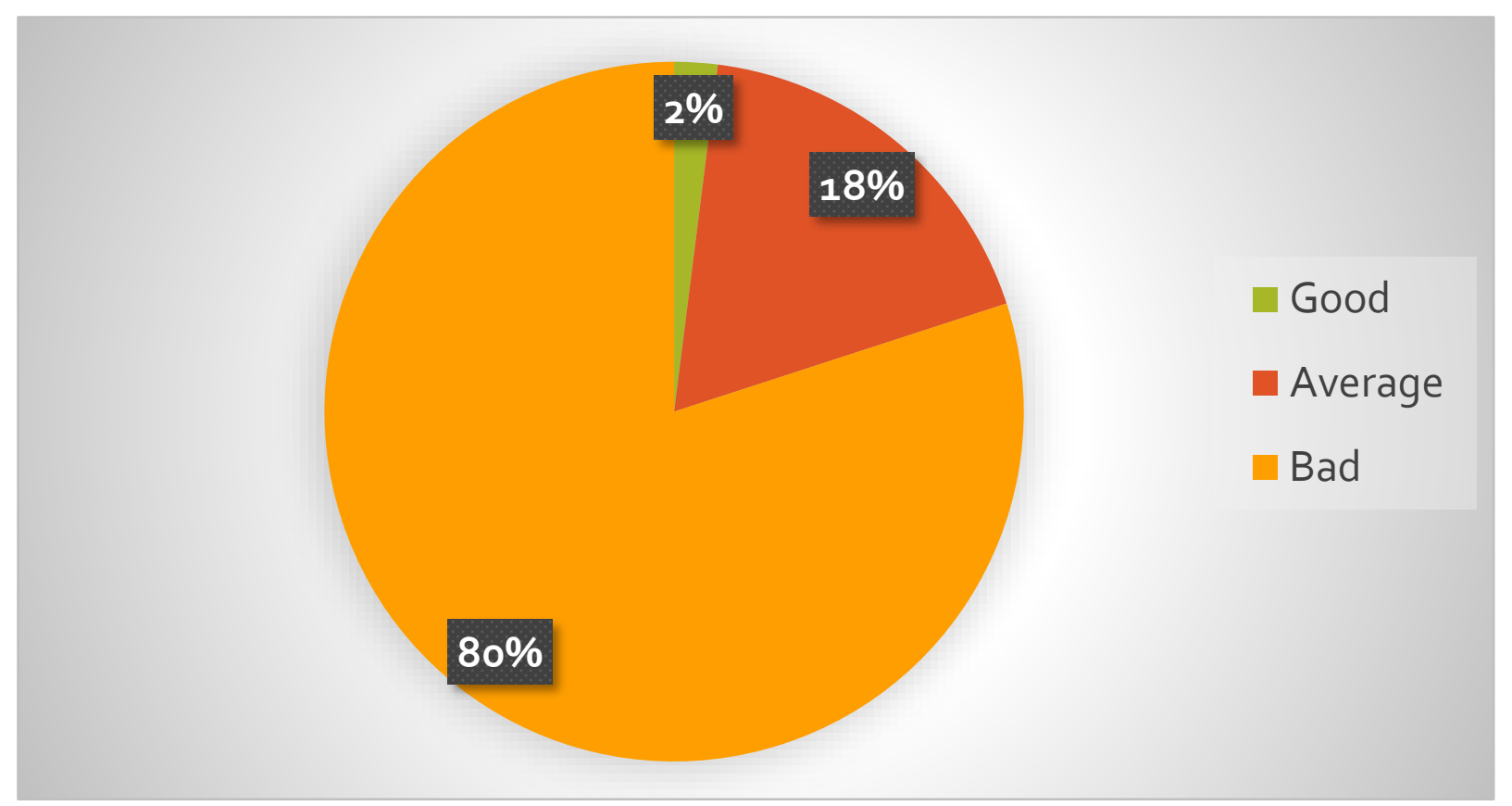

Figure 1: Evaluation of the perception of the quality of pregnancy management by patients

- No statistically significant association was found between assessment of patients' perception of quality of care and mode of delivery $(p=0.82)$.

- The majority of patients in our study population (80\%) were unsatisfied with the medical and paramedical management of their pregnancy, which they rated as poor. It should also be noted that this evaluation of management is global and subjective, and comes right after delivery, the latter thus becoming the most determining element in the evaluation. In addition, giving birth to a woman suffering from vaginismus is a moment of great discomfort and embarrassment, given the need for repeated gynecological examinations during labor and the fear of pain throughout childbirth [2].

\section{CONCLUSIONS}

Childbirth is most often badly experienced by women with vaginismus, whatever the mode of delivery. The experience of gynecological examination and delivery, as well as the lack of caregiver empathy felt by patients about their suffering, would be the most important factors in this assessment. Improving the management of pregnant women with vaginismus could only be achieved through better knowledge of this condition among health professionals in contact with these women.

\begin{tabular}{|c|c|c|c|c|c|}
\hline & & \multicolumn{3}{|c|}{ Perception of the quality of care } & \multirow{2}{*}{$p$} \\
\hline & & Good & Average & Bad & \\
\hline \multirow{3}{*}{ Mode of delivery } & Vaginal delivery & $0(0 \%)$ & $1(2 \%)$ & $9(23 \%)$ & \multirow{3}{*}{0,82} \\
\hline & Emergency caesarean section & $1(2 \%)$ & $3(8 \%)$ & $16(40 \%)$ & \\
\hline & Scheduled cesarean section & $0(0 \%)$ & $3(8 \%)$ & $7(17 \%)$ & \\
\hline
\end{tabular}

